\title{
The Effect of Coupling Agent on the Self-cleaning Ability of Nanowire Zinc Oxide-poly(butylene terephthalate) Fibers
}

\author{
Siripan Metanawin, Napatson Soonthonpinit, and Tanapak Metanawin
}

\begin{abstract}
The aim of this research was to study the effect of the coupling agents, HI-LUBE ${ }^{\mathrm{TM}}$ and Licowax ${ }^{\mathrm{TM}} \mathrm{OP}$ on, rheology properties, thermal properties, mechanical properties and self-cleaning properties of PBT-nanowire $\mathrm{ZnO}$ composite fibers. Variation of the nanowire $\mathrm{ZnO}$ contents in the PBT composite fibers resulted in self-cleaning properties of the fibers. With increase in the amount of nanowire $\mathrm{ZnO}$ in PBT composite fibers, the self-cleaning properties of the PBT composite fibers gradually increased. The $\mathrm{ZnO/PBT}$ composite fibers in presents of $\mathrm{ZnO} 5 \mathrm{wt} \%$ showed the best results of self-cleaning less than $\mathbf{3 0}$ hours of the sunlight which the similar results were found less than 54 hours of 20 watts of UV radiation. Both coupling agents were not affected the self-cleaning properties of the fiber. The Melt Flow Index of the Licowax $^{\mathrm{TM}} \mathrm{OP}$-series sample (L-series) slightly higher than HI-LUBE ${ }^{\mathrm{TM}}$-series sample (E-series) due to the lubricant additive agent increasing the process ability. SEM micrographs showed the fracture surface of the nanowire $\mathrm{ZnO}$ composite fibers at different ratios. The mechanical properties of the ZnO/PBT composite fibers results provide further evident to proof that this composite fibers was able to make textile products. Moreover, the HI-LUBE ${ }^{\mathrm{TM}}$ additive was presented the well mixing between nanowire- $\mathrm{ZnO}$ and PBT due to HI-LUBE ${ }^{\text {TM }}$ is a coupling agent and lubricant while Licowax ${ }^{\mathrm{TM}} \mathrm{OP}$ is a lubricant.
\end{abstract}

Index Terms-Nanocomposite, coupling agent, nanowire-zinc oxide, poly(butylene terephthalate), self-cleaning.

\section{INTRODUCTION}

Many attentions have been focused on the polymer-inorganic nanocomposite materials (PINCs). The use of inorganic nanoparticles into the polymer matrix can provide high-performance novel materials that find applications in many fields such as fuel cell, flammability resistance, biomedical, semiconductor, polymer blend compatibilization, textile [1], [2]. However the retention of homogeneous dispersion of nanosize particle in the preparation process of nanocomposites is very difficult because of strong tendency for nanoparticles to agglomerate. To prevent the formation of agglomerated nanoparticles in

Manuscript received July 1, 2015; revised October 30, 2015. This work was supported by King Mongkut's University of Technology North Bangkok.

Siripan Metanawin and Napatson Soonthonpinit are with the Department of Textile Engineering, Faculty of Engineering, Rajamangala University of Technology Thanyaburi, PathumThani, 12110, Thailand (e-mail: siripan.m@en.rmutt.ac.th, luk_nuying@hotmail.com).

Tanapak Metanawin is with the Department of Materials and Production Technology Engineering, Faculty of Engineering, King Mongkut's University of Technology North Bangkok, Bangkok, 10800, Thailand (e-mail: tanapak.m@eng.kmutnb.ac.th). polymers, the combination of inorganic particles with polymers is usually accomplished by surface modification [2]-[4] and by coupling agents [5], [6]. It is know that coupling agents such as Silane and polypropylene grafted maleic anhydride are an effective way to improve its dispersibility in polymer matrix as well, and hence ameliorate the polymer matrix, thus enhancing the properties of the resulting composites.

Poly(butylene terephthalate) (PBT) is one of the most widely used in automotive, electric, consumer application and textile industry. Beside, PBT also enhances the comprehensive properties of semicrystalline engineering thermoplastic including a high rate of crystallization, good solvent resistance, thermal stability, and excellent processing properties and hence finds its applications in despite its exquisite properties; PBT is very often modified with other polymers and particulate fillers [7].

Nano zinc oxide (nano-ZnO) is well-known environmentally friendly and multifunctional inorganic fillers which exhibits low dielectric constant, large electromechanical coupling coefficient, high luminous transmittance, high catalysis activity, intensive ultra-violet and infrared absorption, self-cleaning ability and etc. However, $\mathrm{ZnO}$ nanoparticles are prone to aggregate due to the large surface area and high surface energy. In order to improve the dispersion, it is necessary to modify the surface of $\mathrm{ZnO}$ nanoparticles [8]-[10] and/or to use coupling agents [5], [6].

Recently, much interest in new materials that can demonstrate photocatalytic behavior under the proper illumination conditions for applications in semiconductor industrials and textile industrials [11]. For this reason, nano zinc oxide (nano-ZnO) has attracted great attention as a semiconductor photocatalyst due to its widely used materials, low cost, good stability, and ease of preparation [12]. One of an interesting application of nano zinc oxide is self-cleaning ability [8].

There has been increased interest in development of permanent self-cleaning on textile materials by the framework of new products classified as technical textiles [13], [14]. However, to date, no research has presented the PBT- nanowire ZnO fibers which designed with special end-use properties. Therefore, in this research we designed an inorganic nanocomposite fibers which have self-cleaning effect. For this purpose, we have prepared nanocomposite fibers using $\mathrm{PBT}$ and nanowire $\mathrm{ZnO}$ with varying the concentration of $\mathrm{ZnO}$ nanoparticles. Two type of coupling agents, HI-LUBE ${ }^{\mathrm{TM}}$ and Licowax ${ }^{\mathrm{TM}}$ OP were used to improve its dispersibility in polymer matrix. 


\section{EXPERIMENTS}

\section{A. Materials}

Poly (butylene terephthalate) (PBT) IQ315 was purchased from Sabic. ZnO nanowire is CAS\#1314-13-2.HI-LUBE ${ }^{\mathrm{TM}}$ was supplied by SINWON chemical Co. Ltd. Licowax ${ }^{\mathrm{TM}} \mathrm{OP}$ powder (LOP, L) was purchased from Clariant. HI-LUPE ${ }^{\mathrm{TM}}$ and $\mathrm{LOP}^{\mathrm{TM}}$ were used as a coupling agent. All samples were used as received. All other chemicals were used as supplied by the companies.

\section{B. Preparation of $\mathrm{ZnO}$ Compound}

The PBT pellets were dried at $80^{\circ} \mathrm{C}$ overnight prior used. The $500 \mathrm{~g}$ of PBT pellets was mixed with $1 \mathrm{wt} \%$, 3wt\% and $5 w t \%$ of $\mathrm{ZnO}$ containing HI-LUBE(E) $0.5 w t \%$ or LOP (L) $0.5 \mathrm{wt} \%$.The glycerol 3 drops were added into the mixture. The $\mathrm{ZnO}$ was blended with PBT using Twin Screw Extruder. The extruder barrel-temperatures zones were set at $240^{\circ} \mathrm{C}$, $250^{\circ} \mathrm{C}, 260^{\circ} \mathrm{C}, 270^{\circ} \mathrm{C}$ and $270^{\circ} \mathrm{C}$, respectively. The screw speed was $80 \mathrm{rpm}$. The obtained $\mathrm{ZnO} / \mathrm{PBT}$ composites were cut into pellet size (Table I).

TABLE I: FORMULATION OF COMPOSITES MATERIALS

\begin{tabular}{ccccccc}
\hline \hline Sample & Materials & Filler & Additive & $\begin{array}{c}\text { PBT } \\
\%(\mathrm{~W} / \mathrm{W})\end{array}$ & $\begin{array}{c}\text { ZnO } \\
\%(\mathrm{~W} / \mathrm{W})\end{array}$ & $\begin{array}{c}\text { Additive } \\
\%(\mathrm{~W} / \mathrm{W})\end{array}$ \\
\hline A & PBT & - & - & 100 & - & - \\
E1 & PBT & ZnO & EBS & 99 & 1 & 0.5 \\
E2 & PBT & ZnO & EBS & 97 & 3 & 0.5 \\
E3 & PBT & ZnO & EBS & 95 & 5 & 0.5 \\
L1 & PBT & ZnO & LOP & 99 & 1 & 0.5 \\
L2 & PBT & ZnO & LOP & 97 & 3 & 0.5 \\
L3 & PBT & ZnO & LOP & 95 & 5 & 0.5 \\
\hline \hline
\end{tabular}

C. Preparation ZnO Fibers

The ZnO/PBT composite pellets were mixed using ThermoHakePolyDrive (Single Screw Extruder). The barrel-temperatures zones were operated at $240^{\circ} \mathrm{C}, 250^{\circ} \mathrm{C}$, $260^{\circ} \mathrm{C}, 270^{\circ} \mathrm{C}$ and $270^{\circ} \mathrm{C}$, respectively. The screw speed was $4 \mathrm{rpm}$. The melting composite exit from the spinneret was draw into the fiber shape. The $\mathrm{ZnO} / \mathrm{PBT}$ fiber was obtained.

\section{Characterizations}

The morphology of the specimens was observed using scanning electron microscope model JSM-5410LV from Jeol, Japan. The cross sectional fracture was obtained by breaking the specimens after freezing in liquid nitrogen. All samples were coated with gold or palladium prior used.

The XRD patterns were measured on PANalyticalX'Pert Pro MPD model pw3040/60 with $\mathrm{Cu}-\mathrm{K}_{\alpha} \mathrm{X}$-ray source from PANalytical, the Netherlands. The diffractometer was scanned from $2 \theta=5^{\circ}-80^{\circ}$.

The melt flow index of the polymer composite compound was evaluated using melt flow indexer model XRL-400A according to ASTM D1238.

The tensile test (tenacity) of the fiber composite was performed on Instron 5569 universal testing machine according to ASTM D3822. The speed of the cross head was $30 \mathrm{~mm} / \mathrm{mm}$.

Thermal properties of the polymer compound were investigated using differential scanning calorimetry model DSC 200 F3 from Netzsch, Germany. The scan were performed from $30^{\circ} \mathrm{C}$ to $300^{\circ} \mathrm{C}$ with heating rate and cooling rate $10^{\circ} \mathrm{C} / \mathrm{min}$ under nitrogen atmosphere.

Moreover, the self-cleaning characteristics of fiber composite were examined under UV-light and Sun light. The coffee stains were created on the samples. Aqueous solution of coffee stain was prepared by mixing $5.5 \mathrm{~g}$ of coffee in $50 \mathrm{~cm}^{3}$ of deionized water. Stained samples were irradiated under sunlight and UV-A lamp 20 watts (Philips, the Netherlands), with $365 \mathrm{~nm}$ wavelength and light intensity of $11.6 \mathrm{~mW} / \mathrm{cm}^{2}$. The self-cleaning property was evaluated based on the coffee stain removal from the fibers.

\section{RESUlTS AND DiscUSSIONS}

\section{A. Melt Flow Index Properties}

The polymer composite compound were prepared by mixing PBT pellets and $\mathrm{ZnO}$ nanowire $1 \mathrm{wt} \%-5 \mathrm{wt} \%$ in the present of HI-LUBE(E-series) or LOP (L-series) using twin screw extruder. The ZnO/PBT composite compound was obtained. To understand the melt properties, the melt flow rate of the polymer composite compound were measured. It was found that the melt flow rate (MFR) were trended to increase with raised the amount loading of $\mathrm{ZnO}$, as seen in Figure 1. The MFR of the L-series samples slightly higher than E-series samples due to the lubricant additive agent increasing the processability. However, MFR at $280^{\circ} \mathrm{C}$ were decreased with increasing the $\mathrm{ZnO}$ (in both of additive E-series and L-series). It was concluded that the melt flow rate at temperature $270^{\circ} \mathrm{C}$ was selected due to its high enough for fiber forming(MFR about 18-22) in the next process.

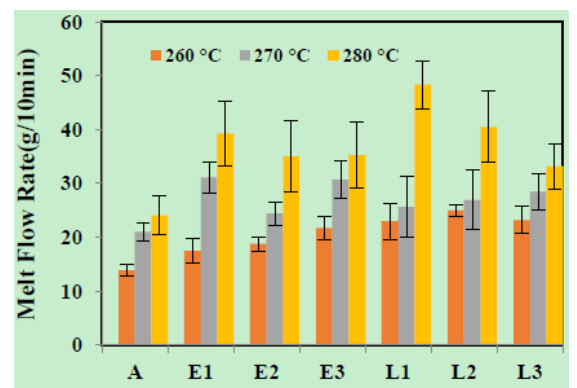

Fig. 1. Melt flow rate of pristine PBT and ZnO/PBT composite of E-series and L-series with various loading amount of $\mathrm{ZnO}$ from 1-5\%wt.

\section{B. X-Ray Diffraction (XRD)}

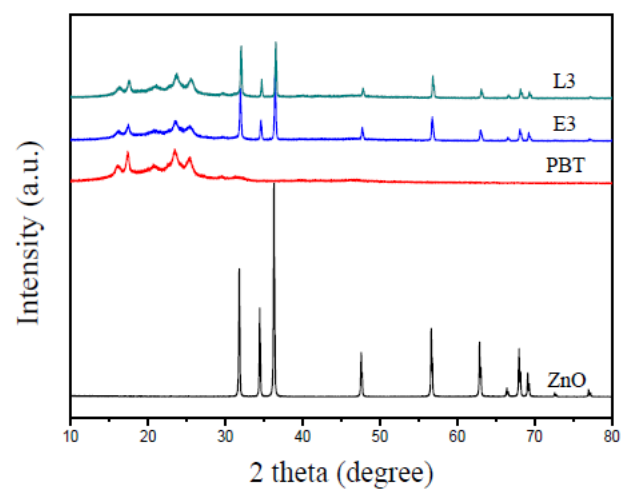

Fig. 2. XRD spectra of pristine ZnO, PBT and E3 and L3.

To understand weather the coupling agents or $\mathrm{ZnO}$ affect to the structure of the polymer composite compound, XDR technique was employed. Fig. 2 presented the XRD spectra of the pristine $\mathrm{ZnO}$ and $\mathrm{ZnO} / \mathrm{PBT}$ composite with $5 \mathrm{wt} \%$ loading amount of $\mathrm{ZnO}$ (E3 and L3). As seen in Figure 2, peaks of pristine $\mathrm{ZnO}$ are presented at $2 \theta=31.7^{\circ}, 34.4^{\circ}, 36.2^{\circ}$, $47.5^{\circ}, 56.6^{\circ}$ and $62.8^{\circ}$ [15]. The results show that both of L3 and E3 spectra presented the combination of $\mathrm{ZnO}$ and PBT in 
each spectrum. Moreover, E3 spectrum was slightly higher than L3 spectrum. It was concluded that E-coupling agent gave the better coupling agent than L-coupling agent. Additionally, both of coupling agents did not affect the structure of the $\mathrm{ZnO} / \mathrm{PBT}$ composite compound.

\section{Thermal Properties}

The thermal properties of the $\mathrm{ZnO} / \mathrm{PBT}$ composite compound were determined using differential scanning calorimetry. Table II shows thermal properties of the $\mathrm{ZnO} / \mathrm{PBT}$ composite compound. The melting temperature was obtained from heating cycle while the crystalline temperature was obtained from cooling cycle. It was found that the $T_{m}$ and $T_{c}$ of the composite sample E1-E3 were not change when increasing the amount loading of $\mathrm{ZnO}$ from $1 \mathrm{wt} \%$ to $5 \mathrm{wt} \%$. The \%crystallinity was decreased at 5\%wt loading of $\mathrm{ZnO}$, as presented in Table II. It indicated that high amount loading of $\mathrm{ZnO}$ affected the crystalline structure. Furthermore, $T_{m}$ and $T_{c}$ of the composite sample L1-L3 were slightly increased when raising the amount loading of $\mathrm{ZnO}$ from $1 \% w t$ to $5 w t \%$. However, the \%crystalline was slightly decreased with $5 \mathrm{wt} \% \mathrm{ZnO}$ loading. It was concluded that E-coupling agent did not affect the $T_{m}$ and $T_{c}$ compare with L-coupling agent. The high loading amount of $\mathrm{ZnO}$ may affect the \%crystalline of the composite compound.

\begin{tabular}{cccc} 
TABLE II: THERMAL PROPERTIES OF ZNO/PBT COMPOUND COMPOSITE \\
\hline \hline Sample & Tm $\left({ }^{\circ} \mathrm{C}\right)$ & Tc $\left({ }^{\circ} \mathrm{C}\right)$ & Crystallinity (\%) \\
\hline A & 216.2 & 182.0 & 31.38 \\
\hline E1 & 216.0 & 185.6 & 26.69 \\
E2 & 216.3 & 185.3 & 28.14 \\
E3 & 215.9 & 185.9 & 24.23 \\
\hline L1 & 216.1 & 184.6 & 30.47 \\
L2 & 215.4 & 183.2 & 30.16 \\
L3 & 218.4 & 189 & 29.84 \\
\hline \hline
\end{tabular}

\section{Morphology}

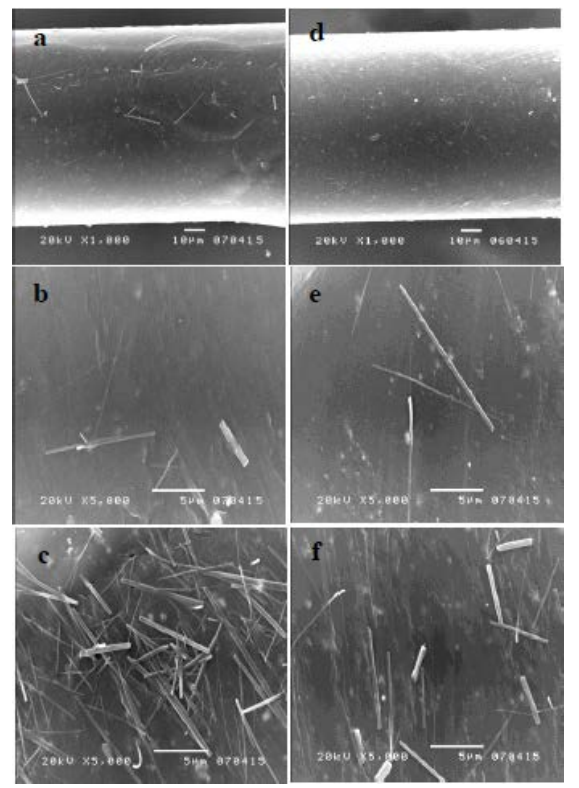

Fig. 3. The SEM images of ZnO/PBT (a) The longitudinal of L2 with 3wt\% $\mathrm{ZnO}$ (b) The fracture surface of L1with $1 \mathrm{wt} \% \mathrm{ZnO}$ (c) The fracture surface of L3with 5wt\% ZnO (d) The longitudinal of E2 with 3wt\% ZnO (e) The fracture surface of E1with $1 \mathrm{wt} \% \mathrm{ZnO}$ and $\mathrm{f}$ ) the fracture surface of E3with $5 \mathrm{wt} \% \mathrm{ZnO}$.
The morphology of the $\mathrm{ZnO} / \mathrm{PBT}$ composite fiber was investigated using scanning electron microscope. The longitudinal study were presented in Fig. 3(a) and Fig. 3(d). The fracture surface of the fiber composite was showed in Fig. 3(b), Fig. 3(c), Fig. 3(e) and Fig. 3(f). It was found that the morphology of the $\mathrm{ZnO}$ was nanowire, as presented in Fig. 3. For longitudinal images, the E2 (Fig. 3(d)) presented the smooth surface comparing to L2 (Fig. 3(a)). As seen in Fig. 3(f), most of the $\mathrm{ZnO}$ nanowire (E3) was located underneath PBT matrix (white dot) while most of $\mathrm{ZnO}$ nanowire (L3) was found on the surface, as seen in Fig. 3(c). It indicated that E-coupling agent was better coupling agent than L-coupling.

\section{E. Mechanical Properties}

The mechanical properties of the $\mathrm{ZnO} / \mathrm{PBT}$ with $\mathrm{ZnO}$ $1 w t \%-5 w t \%$ fiber composite were examined using Instron 5560 universal testing machine. The tensile strength of a fiberistenacity as demonstrated in Fig. 4. The results showed that both of couplings gave similar result. The tenacity of the $\mathrm{ZnO} / \mathrm{PBT}$ fiber composite increased slightly with raised the loading amount of $\mathrm{ZnO} 1 \mathrm{wt} \%-3 \mathrm{wt} \%$. However, the tenacity of L3lower than E3 with 5wt\% loading amount of ZnO. This result was supported by good bonding between $\mathrm{ZnO}$ nanowire and PBT in Fig. 3(f) (E3). It concluded that E-coupling agent offer the better coupling agent over L-coupling at higher loading amount of $\mathrm{ZnO}$.

\section{F. Self-cleaning}

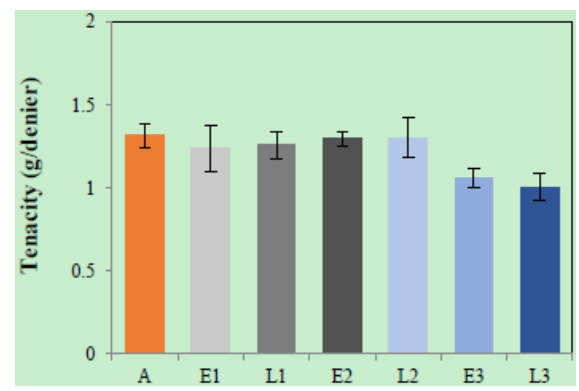

Fig. 4. Tanacity of PBT fiber and ZnO/PBT fiber composite from $1 w t \%-5 w t \%$ of $\mathrm{ZnO}$.

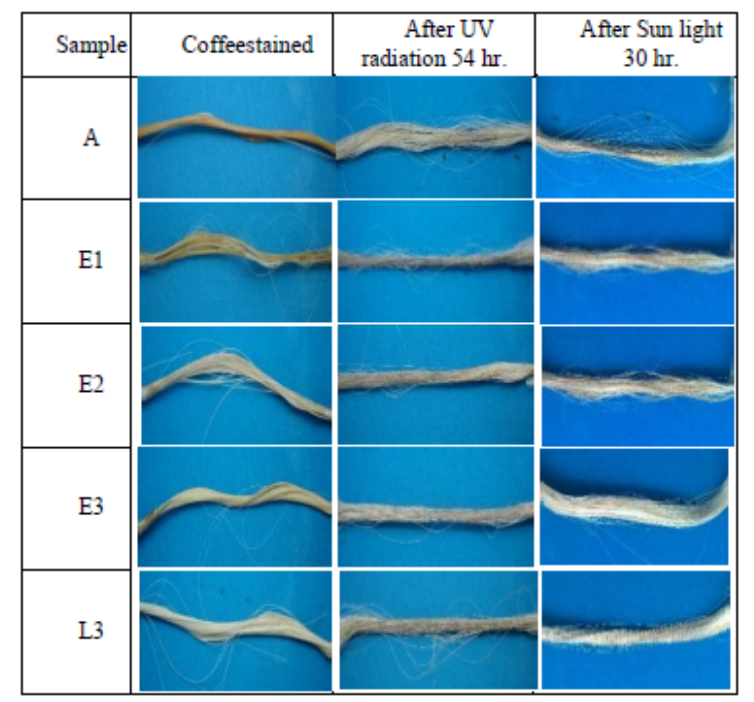

Fig. 5. The photography of the self-cleaning test of the pristine PBT fibers and $\mathrm{ZnO} / \mathrm{PBT}$ composite fibers containing 1wt\%-5wt\% of $\mathrm{ZnOof}$ unstained-coffee and stained-coffee under sun light and 20 watt UV radiation.

The self-cleaning properties of the nanowire $\mathrm{ZnO} / \mathrm{PBT}$ 
composite fibers which coffee-stained were examined under sunlight and 20 watts of UV radiation. The result shown that the coffee stained on the $\mathrm{ZnO} / \mathrm{PBT}$ composite fibers was decreased when increased loading amount of $\mathrm{ZnO}$ from $1 \mathrm{wt} \%$ to $5 \mathrm{wt} \%$. The coffee-stained on the composite fibers containing $5 \%$ wt of $\mathrm{ZnO}$ was relatively removed under UV radiation for 54 hours which similar results was found under 30 hours of Sun light. Both of coupling agents were not affect the self-cleaning properties of the composite fibers, as seen in Fig. 5 (E3 and L3).

\section{CONCLUSION}

The polymer nanocomposites had been successfully investigated. The effect of the coupling agents, HI-LUBE ${ }^{\mathrm{TM}}$ and Licowax ${ }^{\mathrm{TM}} \mathrm{OP}$ on the, rheology properties, thermal properties, mechanical properties and self-cleaning properties of polymer nanocomposite were also studied. The nanowire-Zinc oxide (nanowire-ZnO) were blend with the poly(butylene terephthalate) (PBT) at $1 \mathrm{wt} \%$, 3wt $\%$ and $5 w t \%$. The nanowire-ZnO/PBT composite fibers were obtained from single screw extruder by using melt spinning technique. The results showed that the melt flow rates (MFR) were trended to increase with raised the amount loading of nanowire $\mathrm{ZnO}$. Furthermore, The MFR of the Licowax ${ }^{\mathrm{TM}} \mathrm{OP}$ -series sample (L-series) slightly higher than HI-LUBE ${ }^{\mathrm{TM}}$-series sample (E-series). Both of coupling agents did not affect the structure and thermal properties and self-cleaning properties of the $\mathrm{ZnO} / \mathrm{PBT}$ composite fibers. In additionally, the high loading amount of nanowire-ZnO may affect the \%crystalline of the polymer nanocomposite. The morphology of the nanowire $\mathrm{ZnO} / \mathrm{PBT}$ composite fiber were also investigated by using SEM. It was noticed that fine nanowire-ZnO dispersion were observed with respected to the loading amount of $\mathrm{ZnO}$. However, the HI-LUBE ${ }^{\mathrm{TM}}$ additive was presented the well mixing between nanowire-ZnO and PBT. Variation of the nanowire $\mathrm{ZnO}$ content in the PBT composite fibers resulted in self-cleaning properties of the fibers. With raised the amount of nanowire $\mathrm{ZnO}$ in PBT composite fibers, the self-cleaning properties of the PBT composite fibers gradually increased. The ZnO/PBT composite fibers in the presents of $\mathrm{ZnO} 5 \mathrm{wt} \%$ showed the best results of self-cleaning fewer than 30 hours of the sunlight which similar results were found under 54 hours of 20 watts of UV radiation. The mechanical properties of the $\mathrm{ZnO} / \mathrm{PBT}$ results provide further evident to proof that this composite fibers was able to make a textile products.

\section{ACKNOWLEDGMENT}

I would like to thank King Mongkut's University of Technology North Bangkok for financial support.

\section{REFERENCES}

[1] D. R. Paul and L. M. Robeson, "Polymer nanotechnology: Nanocomposites,” Polymer, vol. 49, no. 15, pp. 3187-3204, 2008.

[2] M. Sato, A. Kawata, S. Morito, Y. Sato, and I. Yamaguchi, "Preparation and properties of polymer/zinc oxide nanocomposites using functionalized zinc oxide quantum dots," European Polymer Journal, vol. 44, pp. 3430-3438, 2008.
[3] P. Panutumrong, M. Metanawin, S. Metanawin, and N. O-Charoen, "The effect of nano-Zinc oxide on the self-cleaning properties of cotton fabrics for textile application," in Proc. the 4th International Symposium on the Fusion Technologies, RUS, Huntra campus, Thailand, 2011, p. 13.

[4] N. Elamin and A. Elsanousi, "Synthesis of ZnO Nanostructures and their photocatalytic activity," Journal of Applied and Industrial Sciences, vol. 1, pp. 32-35, 2013.

[5] S. Mallakpour and M. Madani, "Use of silane coupling agent for surface modification of zinc oxide as inorganic filler and preparation of poly(amide-imide)/zinc oxide nanocomposite containing phenylalanine moieties,” Bulletin Materials Science, vol. 35, no. 3, pp. 333-339, 2012.

[6] H. J. O’Donnell and D. G. Bairdt, "In situ reinforcement of polypropylene with liquid-crystalline polymers: Effect of maleic anhydride-grafted polypropylene,” Polymer, vol. 36, no. 16, pp. 3113-3126, 1995.

[7] G. S. Deshmukh, D. R. Peshwe, S. U. Pathak, and J. D. Ekhe, “A study on effect of mineral additions on the mechanical, thermal, and structural properties of poly(butylene terephthalate) (PBT) composites,' Journal of Polymer Research, vol. 18, pp. 1081-1090, 2011.

[8] A. Hamrouni, H. Lachheb, and A. Houas, "Synthesis, characterization

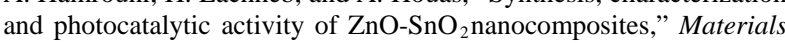
Science and Engineering B, vol. 178, pp. 1371-1379, 2013.

[9] J. H. Sun, S. Y. Dong, Y. K. Wang, and S. P. Sun, "Preparation and photocatalytic property of a novel dumbbell-shaped $\mathrm{ZnO}$ microcrystal photocatalyst," Journal of Hazardous Materials, vol. 172, pp. 1520-1526, 2009

[10] E. Yassitepe, H. C. Yatmaz, C. Öztürk, K. Öztürk, and C. Duran, "Photocatalytic efficiency of $\mathrm{ZnO}$ plates in degradation of azo dye solutions," Journal of Photochemistry and Photobiology A: Chemistry, vol. 198, pp. 1-6, 2008.

[11] K. T. Meilert, D. Laub, and J. Kiwi, "Photocatalytic self-cleaning of modified cotton textiles by $\mathrm{TiO}_{2}$ clusters attached by chemical spacers," Journal of Molecular Catalysis A: Chemical, vol. 237, pp. 101-108, 2005

[12] R. Fateh, R. Dillert, and D. Bahnemann, "Self-cleaning properties, mechanical stability, and adhesion strength of transparent photocatalytic $\mathrm{TiO}_{2}-\mathrm{ZnO}$ coatings on polycarbonate," Applied Materials \& Interfaces, vol. 6, no. 4, pp. 2270-2278, 2014.

[13] T. Yuranova, R. Mosteo, J. Bandara, D. Laub, and J. Kiwi, "Self-cleaning cotton textiles surfaces modified by photo-active $\mathrm{SiO}_{2}$, $\mathrm{TiO}_{2}$ coating,” Journal of Molecular Catalysis A: Chemical, vol. 244, pp. 160-167, 2006.

[14] L. Karimi, M. Mirjalili, M. E. Yazdanshenas, and A. Nazari, "Effect of nano TiO2 on self-cleaning property of cross-linking cotton fabric with succinic acid under UV irradiation,” Photochemistry and Photobiology, vol. 86, pp. 1030-1037, 2010.

[15] N. Elamin and A. Elsanousi, "Synthesis of $\mathrm{ZnO}$ nanostructures and their photocatalytic activity," Journal of Applied and Industrial Sciences, vol. 1, no. 1, pp. 32-35, 2013.

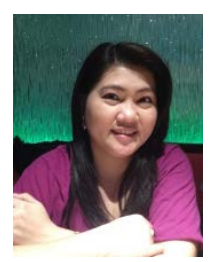

Siripan Metanawin joined Prof. Sébastien Perrier and Prof. Jim Guthrie's group at School of Chemistry, Faculty of Mathematics and Physical Sciences, University of Leeds, U.K. in 2006. She received the Ph.D. degree (major in biodegradable, polymer synthesis, living polymer) in 2011. The special topic is "Biodegradable polymerization via RAFT". She is a lecturer on synthetic polymer at Department of Textile Engineering, Faculty of Engineering, Rajamangala University of Technology Thanyaburi (Rmutt), Thailand. She is currently the member of polymer and colloid group at Kmutnb. Her current research interests are including the design of a wide range of state-of-the-art functional polymeric materials (e.g. miniemulsion polymerization, living polymerization, ring-opening polymerization), nanotechnology (e.g. polymer nanocomposite), hybrid materials (e.g. polymer hybrid) and fiber forming (melt spinning, electrospinning etc.).

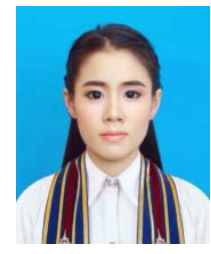

Napatson Soonthonpinit joined Dr. Tanapak Metanawin and Dr. Siripan Metanawin's group at Department of Textile Engineering, Faculty of Engineering, Rajamangala University of Technology Thanyaburi (Rmutt), Thailand in 2013. She received the B.E. degree (major in fiber forming, polymer synthesis) in 2015. The special topic is "The preparation polymer fiber composite form poly (butylene terephthalate) for self-cleaning approach”. She is a currently research assistance at polymer and colloid group at Kmutnb where she conducted research in polymer nanocomposite and polymer hybrid material. 


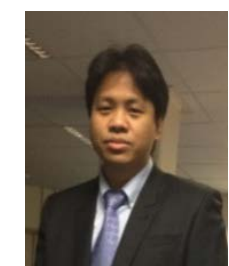

Tanapak Metanawin joined Prof. Sébastien Perrier and Assoc. Prof. Xiaosong Wang's group at School of Chemistry, Faculty of Mathematics and Physical Sciences, University of Leeds, U.K. in 2007. He received the Ph.D. degree (Major in colloid, polymer synthesis, nano technology and living polymer) in 2011. The special topic is "Synthesis and characterization of materials obtained by living radical polymerization”. He is a lecturer on polymer composite at Department of Material and Production Technology Engineering, Faculty of Engineering, King Mongkut's university of technology north Bangkok (Kmutnb), Thailand.
He is currently the leader of polymer and colloid group at Kmutnb. His current research interests in the area of functional polymeric materials (e.g miniemulsion polymerization, polymer self-assembly, living polymerization), polymer composite, nanotechnology (e.g. polymer nanocomposite), hybrid materials (e.g. polymer hybrid) and fiber forming (melt spinning, electrospinning etc.). One of his selected publications is $\mathrm{T}$. Metanawin, T. Tang, R. Chen, D. Vernon, and X. Wang, "Cytotoxicity and photocytotoxicity of structure-defined water-soluble C60/micelle supramolecular nanoparticles,” Nanotechnology, vol. 22, 2011. 